\title{
Status Quo of College Students' Bad Exercise Habits and Its Influencing Factors
}

\author{
Xiangle Meng \\ College of Physical Education \\ Yan'an University \\ Yan'an, Shaanxi 716000
}

\begin{abstract}
Objective: to investigate the status quo and the influencing factors of college students' bad exercise habits. Methods: select 500 college students randomly, and carry out investigation with self-designed questionnaire. Use descriptive statistics and chi-square test to make analysis. Results: The students have a very high recognition rate of "bad exercise habits are not conducive to health". But the majority of students have bad exercise habits. And college students lack the understanding of the meaning and manifestation of bad exercise habits. College Students' bad exercise habits are diversified, and the main manifestation forms are the neglect of relax exercise after sport, lack of perseverance, insufficient preparations before exercise, lack of attention, and easy influence of others. Conclusion: bad exercise habits are common among college students. College students' awareness of bad habits is not optimistic, so it is urgent to eliminate their bad exercise habits by increase the degree of ideological attention and knowledge about exercise.
\end{abstract}

Keywords-college students; bad exercise habits; status quo; influencing factors

\section{INTRODUCTION}

To develop a good exercise habit is the key to lay the lifelong foundation for the students' physical education. The good exercise habits can effectively enhance the individual's psychological and social adaptation ability[2]. As an important part of college students' learning, physical exercise is very popular among college students. However, the bad habit of physical exercise can easily lead to acute injury, exercise discomfort and chronic diseases of digestive system, and then affect the students' emotion and learning. Therefore, good physical exercise habit is the guarantee of obtaining the benefit of exercise. At present, the research on the exercise habit is focused on influencing factors of good exercise habits, and the methods and ways [3-5] of the cultivation of good physical exercise habits, which are seldom involved in the study of the status quo and the influencing factors of the bad exercise habits. Therefore, this study through the investigation of college students' bad habits, is aimed to eliminate bad exercise habits, and provide empirical evidence for the improvement of exercise efficiency through investigating students' awareness of bad habits, what bad exercise habits are, and the factors leading to bad exercise habits. The results of the survey are as follows.

\section{OBJECT AND METHOD}

\section{A. Objects}

Randomly selected 500 college students in a university in Shaanxi Province as the object of investigation from September 10, 2015 to September 16, 2015. Among them, there were 250 boys and 250 girls; there were 125 freshmen, 125 sophomores, 125 junior students and 125 senior students; there were 100 students of PE major and 400 students of non-PE major. The average age was within the range of 20.4 \pm 2.9 .

\section{B. Methods}

Use self-designed bad exercise habits questionnaire. The content of the questionnaire includes 4 parts, instruction, personal basic information, principal part and acknowledgment. It needs about 10 minutes to finish a questionnaire. There are 6 questions in principal part, including closed type and semi-closed type. In the sports area, accommodation area, teaching area and other places, randomly deliver 572 questionnaires according to sex, major, grade and preset proportion of the number. Collect 570 questionnaires on the spot and 500 copies are valid.

\section{Statistical Analysis}

Use SPSS 19 to do descriptive analysis and chi square test. If $\mathrm{P}$ is less than $0.05(\mathrm{P}<0.05)$, it indicates that the data have statistical significance.

\section{RESULTS AND ANALYSIS}

\section{A. Overall Situation of College Students' Bad Exercise Habits}

The survey shows that when it comes to "How do you know about 'the influence of bad exercise habits on health'?", no college students select "conducive to health". $99.2 \%$ (496/500) of college students choose "not conducive to health". $0.8 \%(4 / 500)$ of college students selects "no effect". It is obvious that the majority of college students have a clear understanding of the role of bad exercise habits. They can realize the negative effect of bad exercise habits regardless of gender, grade and major "Table 1". 
TABLE I. UNDERSTANDING OF COLLEGE STUDENTS ON EFFECT OF BAD EXERCISE HABITS ON HEALTH (THE NUMBER: \%)

\begin{tabular}{|c|c|c|c|c|c|}
\hline Item & $\begin{array}{l}\text { Conducive } \\
\text { to health }\end{array}$ & $\begin{array}{c}\text { Not } \\
\text { conducive to } \\
\text { health }\end{array}$ & No effect & $\mathbf{x}^{2}$ & $\mathbf{P}$ \\
\hline Male & $0(00.0)$ & $250(50.0)$ & $0(0.0)$ & 2.27 & $\begin{array}{c}> \\
0.05\end{array}$ \\
\hline Female & $0(00.0)$ & $246(49.2)$ & $4(0.8)$ & & \\
\hline $\begin{array}{c}\text { freshm } \\
\text { an }\end{array}$ & $0(00.0)$ & $122(24.4)$ & $3(0.6)$ & 6.05 & $\begin{array}{c}> \\
0.05\end{array}$ \\
\hline $\begin{array}{l}\text { Sopho } \\
\text { more }\end{array}$ & $0(00.0)$ & $124(24.8)$ & $1(0.2)$ & & \\
\hline Junior & $0(00.0)$ & $125(25.0)$ & $0(0.0)$ & & \\
\hline Senior & $0(00.0)$ & $125(25.0)$ & $0(0.0)$ & & \\
\hline $\mathrm{PE}$ & $0(00.0)$ & $100(20.0)$ & $0(0.0)$ & 0.14 & $\begin{array}{c}> \\
0.05\end{array}$ \\
\hline $\begin{array}{l}\text { Non- } \\
\text { PE }\end{array}$ & $0(00.0)$ & $396(79.2)$ & $4(0.8)$ & & \\
\hline
\end{tabular}

TABLE II. UNDERSTANDING OF COLLEGE STUDENTS ON “THE MEANING OF BAD EXERCISE HABITS” (THE NUMBER: \%)

\begin{tabular}{|c|c|c|c|c|c|}
\hline Item & $\begin{array}{c}\text { Conduciv } \\
\text { e to } \\
\text { health }\end{array}$ & $\begin{array}{c}\text { Not } \\
\text { conducive to } \\
\text { health }\end{array}$ & No effect & $\mathbf{x}^{2}$ & $\mathbf{P}$ \\
\hline Male & $23(6.8)$ & $215(40.8)$ & $12(2.4)$ & 2.29 & $\begin{array}{c}> \\
0.05 \\
\end{array}$ \\
\hline Female & $15(5.6)$ & $219(41.2)$ & $16(3.2)$ & & \\
\hline $\begin{array}{c}\text { freshma } \\
n\end{array}$ & $6(1.2)$ & $111(22.2)$ & $8(1.6)$ & 3.29 & $\begin{array}{c}> \\
0.05\end{array}$ \\
\hline $\begin{array}{c}\text { Sopho } \\
\text { more }\end{array}$ & $8(2.2)$ & $110(21.4)$ & $7(1.4)$ & & \\
\hline Junior & $12(4.2)$ & $106(19.4)$ & $7(1.4)$ & & \\
\hline Senior & $12(4.8)$ & $107(19.0)$ & $6(1.2)$ & & \\
\hline $\mathrm{PE}$ & $11(2.2)$ & 87 (17.4) & $2(0.4)$ & 4.80 & $\begin{array}{c}> \\
0.05 \\
\end{array}$ \\
\hline Non-PE & $\begin{array}{c}27 \\
(10.2)\end{array}$ & $347(64.6)$ & $26(5.2)$ & & \\
\hline
\end{tabular}

TABLE III. STATUS QUO OF COLLEGE STUDENTS ON "DO YOU HAVE BAD EXERCISE HABITS?” (THE NUMBER: \%)

\begin{tabular}{|c|c|c|c|c|c|}
\hline Item & yes & no & $\begin{array}{l}\text { Don't } \\
\text { know }\end{array}$ & $x^{2}$ & $\mathbf{P}$ \\
\hline Male & $8(6.8)$ & $\begin{array}{c}238 \\
(40.8)\end{array}$ & $4(2.4)$ & 2.29 & $>0.05$ \\
\hline Female & $5(5.6)$ & $\begin{array}{c}235 \\
(41.2)\end{array}$ & $\begin{array}{c}10 \\
(3.2)\end{array}$ & & \\
\hline $\begin{array}{c}\text { freshma } \\
n\end{array}$ & $2(0.4)$ & $\begin{array}{c}116 \\
(22.1)\end{array}$ & $7(1.4)$ & 8.68 & $>0.05$ \\
\hline $\begin{array}{c}\text { Sophom } \\
\text { ore }\end{array}$ & $3(0.6)$ & $\begin{array}{c}118 \\
(23.6)\end{array}$ & $4(0.8)$ & & \\
\hline Junior & $3(0.6)$ & $\begin{array}{c}119 \\
(23.8)\end{array}$ & $3(0.6)$ & & \\
\hline Senior & $5(1.0)$ & $\begin{array}{c}120 \\
(24.0)\end{array}$ & $0(0.0)$ & & \\
\hline $\mathrm{PE}$ & $4(0.8)$ & $96(19.2)$ & $0(0.4)$ & 4.47 & $>0.05$ \\
\hline Non-PE & $9(1.8)$ & $\begin{array}{c}377 \\
(75.4)\end{array}$ & $\begin{array}{c}14 \\
(5.2)\end{array}$ & & \\
\hline
\end{tabular}

When it comes to "Do you know the meaning of bad exercise habits?", 7.6\% (38/500) of college students select "yes"; $86.8 \%$ (434/500) students select "do not know much (know but not clear); $5.6 \%(28 / 500)$ students select "don't know". It can be seen that the vast majority of students do not know the meaning of bad exercise habits profoundly regardless of gender, grade and major "Table 2".

When it comes to "Do you have bad exercise habits?", $2.6 \%(13 / 500)$ of the students select "no"; $94.6 \%(473 / 500)$ of the students select "yes"; and 2.8\% (14/500) of the students select "don't know". It shows that most of the students have bad exercise habits and the number of college students with bad exercise habits is regardless of gender, grade and major "Table 3".

When it comes to "How many bad exercise habits do you know?", 45\% (225/500) of college students select " $\leq 2$ "; $35 \%$ $(175 / 500)$ of college students select " 3 "; $20 \%(100 / 500)$ of college students select " $\geq 4$ ". It can be seen that the number of bad exercise habits they know are different, and there are differences in this aspect among students with different gender, grade and major "Table 4".

TABLE IV. STATUS QUO OF COLLEGE STUDENTS ON "HOW MANY BAD EXERCISE HABITS DO YOU KNOW?" (THE NUMBER:\%)

\begin{tabular}{|l|l|l|l|l|l|}
\hline \multicolumn{1}{|c|}{ Item } & \multicolumn{1}{|c|}{$\mathbf{2}$} & \multicolumn{1}{c|}{$\mathbf{3}$} & $\mathbf{1 4}$ & \multicolumn{1}{|c|}{$\mathbf{x}^{\mathbf{2}}$} & $\mathbf{P}$ \\
\hline Male & $71(14.2)$ & $\begin{array}{l}106 \\
(21.2)\end{array}$ & $73(14.6)$ & $\begin{array}{l}60.9 \\
6\end{array}$ & $\begin{array}{l}< \\
0.05\end{array}$ \\
\hline Female & $\begin{array}{c}154 \\
(23.4)\end{array}$ & $69(13.8)$ & $27(5.4)$ & & \\
\hline $\begin{array}{l}\text { freshm } \\
\text { an }\end{array}$ & $94(18.8)$ & $23(4.6)$ & $8(1.6)$ & $\begin{array}{l}84.2 \\
3\end{array}$ & $\begin{array}{l}< \\
0.05\end{array}$ \\
\hline $\begin{array}{l}\text { Sopho } \\
\text { more }\end{array}$ & $62(19.4)$ & $42(8.4)$ & $21(4.2)$ & & \\
\hline Junior & $41(8.2)$ & $49(9.8)$ & $35(7.0)$ & & \\
\hline Senior & $28(5.6)$ & $61(12.2)$ & $36(7.2)$ & & \\
\hline $\begin{array}{l}\text { PE } \\
12(2.4)\end{array}$ & $35(7.0)$ & $53(10.6)$ & 98.8 & $<$ \\
\hline $\begin{array}{l}\text { Non- } \\
\text { PE }\end{array}$ & 213 & 140 & $47(9.4)$ & & 0.05 \\
\hline
\end{tabular}

B. The Manifestation Forms of Bad Exercise Habits of College Students

The classification of bad exercise habits and the statistical results shows that the bad exercise habits of college students are diversified. There are up to $10 \mathrm{bad}$ exercise habits. The Pareto analysis shows several major bad exercise habits, including neglect of relax exercise after exercise, lack of perseverance, no warm-up activities before exercise, a large amount of liquid replenishment during or after exercise, and cooling with cold or icy liquid during or after exercise. The analysis results are shown in "Fig. 1". 


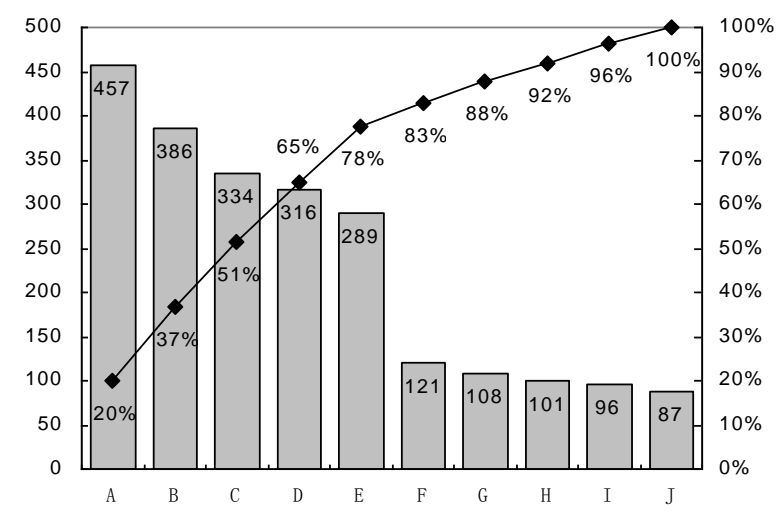

Note: A: neglect of relax exercise after exercise; B: lack of perseverance; C: no warm-up activities before exercise; D: a large amount of liquid replenishment during or after exercise; $\mathrm{E}$ : cooling with cold or icy liquid during or after exercise; F: exercise on an empty stomach; G: ignoring to keep warm after exercise and sweat; H: exercise before sleep; I: breath with mouth; J: dressing at will during exercise

Fig. 1. Pareto Analysis on Colleges Students' Bad Exercise Habits

Chi square test results show that there are differences $(\mathrm{x} 2=22.14,19.23, \mathrm{P}<0.05)$ on the bad exercise habits of a large amount of liquid replenishment during or after exercise, and cooling with cold or icy liquid during or after exercise among students with different gender; there are differences $(\mathrm{x} 2=38.67, \mathrm{P}<0.05)$ on the bad exercise habit of no warmup activities before exercise among students of different major. Among them, boy students like to replenish liquid and cool body with cold or icy liquid than girl students. Students of PE major pay more attention to warm-up activities than students of non-PE major. There are no difference on other 7 bad exercise habits among students of different grade, gender and major.

\section{The Influencing Factors of Bad Exercise Habits of College Students}

Survey shows that students' answers on "What causes you develop bad exercise habits?" are relatively concentrated (multiple choice/students are allowed to fill other contents by themselves). It can be summed up for 3 factors, including the lack of related knowledge, lack of attention and the influence of others. Among them, $94.1 \%$ of college students think that PE teachers do not tell them previously, and thus they lack relevant knowledge and go into "misunderstanding". $86.2 \%$ of college students are aware that bad exercise habits are not conducive to health, but they do not pay enough attention to it. $46.7 \%$ of college students think that they are affected by peers, producing a "herd mentality". In the absence of relevant knowledge, the number of female students is a little more than that of male students; junior and senior students are relatively less; the students of PE major learn more about the physical education than students of non-PE major. The chi square analysis shows that there are differences ( $\mathrm{x} 2=53.68, \mathrm{P}<0.05)$ on the lack of relevant knowledge among students of PE major and students of non-PE major. In the degree of attention, girls pay more attention to exercise habits than boys; senior and junior students are relatively less; students of PE major relatively pay more attention to exercise habits than students of non-PE major.
The Pareto analysis shows that there is no difference ( $\mathrm{x} 2=4.6$, $5.3,2.9, \mathrm{P}>0.05)$ on the lack of ideological attention among students of different gender, grade and major. In the influence of others, the boys are more likely to be influenced by others, and freshmen and sophomore are more likely to be influenced by their peers, and the students of non-PE students are more likely to be influenced by others. The Pareto analysis also shows that there is no difference on the influence of others among students with different gender, grade and major $(\mathrm{x} 2=7.2,5.7,3.6, \mathrm{P}>0.05)$.

\section{CONCLUSION}

On the whole, the proportion of college students that recognize the effect of bad exercise habits is very high, regardless of gender, major and grade. It shows that students have a consistent understanding of the common sense that "bad exercise habits are not conducive to health". However, the proportion of college students that know the meaning of "bad exercise habit" is very low. The proportions of boys, senior grades and PE major are relatively slight higher than those of girls, junior grades and non-PE major, but there is no considerable difference. It shows that the college students have a bad understanding of "its professional meaning or definition". There is no gender, major and grade difference among students who select "yes" on "Do you have bad exercise habits?", which shows that the bad habits are common among college students. But there is difference among students on "listing the number of bad exercise habits" with different gender, grade and major. The main manifestations are that boys, students of senior grades and of PE major could list more examples respectively than girls, students of junior grades and of non-PE major. Some studies have pointed out that, compared with girls, boys love sports more and their participation degree are higher than that of girls[6-7], so the boys' training experience and knowledge accumulated are often more than girls. Students of senior grades have more exercise experience than students of junior grades, so students of senior grades could recognize more bad exercise habits than students of junior grades. Students of PE major have both technological and physical exercise and professional knowledge, so they have a deep understanding of the specific forms of bad habits.

Yang Zhaochang's survey on bad exercise habits of college students after school shows that the main manifestation forms [8] are insufficient warm-up before sports, eating just before or immediately after exercise, drinking a lot of icy water during sports or after exercise, ignoring to keep warm after exercise, often dressing at will during sports and etc. This survey shows that there are diversified bad exercise habits and main manifestations are neglect of relax exercise after exercise, lack of perseverance, insufficient warm-up activities before exercise, a large amount of liquid replenishment during or after exercise, and cooling with cold or icy liquid during or after exercise. It can be seen that the students have both common and personality on bad exercise habits. The warm-up activity before exercise can mobilize body's function and avoid sports injury. The relax activities after exercise is conducive to the rapid recovery of the body function [9]. They are the content of 
physical education and common sense. But college students' bad exercise habits are mainly manifested in these aspects. Sweating, thirst, and increase of body temperature are inevitable phenomena in physical exercise. Drinking a lot of liquid or reducing body temperature with cold water after exercise may increase burden of the stomach, blood vessels and skin, resulting in spasm, pain and syncope. In addition, ignoring to keep warm will be easy to catch a cold, and thus affect daily learning and life. Perseverance is important in physical exercise. The study shows that the weight and the percentage of body fat of middle-aged women who exercised for 6 months can be effectively improved and the incidence of obesity can be effectively controlled [10].

This study shows that "lack of relevant knowledge" is the most important factor that affects college students to develop a good exercise. The promotion effect of physical exercise on physical and mental health has been confirmed by a large number of studies [11-13], but it shall be built on scientific and reasonable exercise habits. Therefore, the understanding of college students on common sense can improve the degree of recognition on "bad exercise habits are not conducive to health". The cultivation of college students' exercise knowledge, exercise skills and exercise habits is mainly the task of physical education. But in general it is not taken seriously in physical education. Teachers often give teaching in sheep herding style, or even let other subjects take place of $\mathrm{PE}$ class [14]. The physical education teaching is characterized by techniques and physical exercises. PE teachers often think little of theory teaching, resulting that students cannot get enough exercise knowledge from the sports class, thus a lot of college students seriously lack understanding of the meaning and manifestation forms of bad exercise habits. This study also shows that "lack of ideological attention" and "influence of others" are also important factors. College students still have bad exercise habits even when they have recognized the bad effect of bad exercise habits, and they do not go to understand the relevant knowledge of bad habits. It indicates that college students do not give enough attention ideologically. The reason is that there is an incubation period before bad exercise habits has caused a bad effect on body, or they think the bad effect is not big enough to cause a warning, or the bad effect may disappear after a short period. So many college students may think bad exercise habits may not cause irreparable damage to health. Peer relationship is an important factor [15] to influence college students' exercise habits. College students tend to go together to exercise, so they are affected by peers and other people. Other people's exercise behavior and habits will give a model role to the observers. If exercisers' discrimination power is not strong, they may be driven by group psychology and easy to acquire bad habits. All these fully indicate that college students do not attach importance to exercise habit ideologically, lack adequate knowledge of exercise, and lack perseverance in exercise.

\section{REFERENCES}

[1] Wang Dongqiao, Wang Hong \& Sun Lu. To develop A Good Exercise Habit is the Key to Lay the Lifelong Foundation for Physical Education. Journal of Beijing Sport University, 2001, 24 (4): 540-541.
[2] Zhang Qiuying \& Kong Chuihui. Physical Health Conditions and Exercise Habit Developing Modes of Student Groups with Different Exercise Habits. Journal of Beijing Sport University, 2009, 32 (6): 44-47.

[3] Qiao Yucheng. The Forming Mechanism and Influence Factors of Exercise Habits of Teenagers. Journal of Physical Education, 2011, 18 (3): 87-94

[4] Song Shan, Li Dapeng. Research on Current Situation and Countermeasures of College Students' Physical Exercise Habits, Journal of Sports Technology Literature 2012, 20 (3): 91-93.

[5] Zhang Guiting, Jing Qiao. Research on Influencing Factor System of College Students' Physical Exercise Habit. Journal of Beijing Sport University, 2008, 31 (5): 669-670.

[6] Zhong Zhenxin, Yao Lei. Research on College Students' Physical Exercise Habits. China Sports Science and Technology, 2003, 39(3): 27-29.

[7] Li Shujuan \& Ren Hongbo. Survey Research on Inner Mongolia University Students' Physical Exercise Attitude and Exercise Habits. Inner Mongolia Normal University Journal (NATURAL SCIENCE CHINESE EDITION), 2013, 42 (6): 739-742.

[8] Chen Kaihua, Wu Xiaoyan. Research on the Relationship of Physical Exercise, Emotion and Sleep of College Students in Anhui Province. Journal of Chinese School Health, 2015, 36(5): 715-717.

[9] Duan Yimei, Duan Zhaoying \& Kang Xiaohui, et al. Gender Difference Analysis on the Influence of Certain University Firstgrade Students' Physical Exercise on Anxiety and Depression. Journal of Chinese School Health, 2014, 35 (5): 756-757.

[10] Yuan Guiyong, Zhang Meiling. Influence of Middle School Students' Physical Exercise on Self Efficacy and Self-esteem and Subjective Well Being. Journal of Chinese School Health, 36, 2015 (3): 442-443.

[11] Gong Pingwang, Liu Qing. Investigation on Influence Factors of SelfEfficacy Sense of PE Teachers in Middle School. Journal of Sports Adult Education, 2010, 26 (1): 90-92.

[12] Mo Lianfang. Relationship of Peers and College Students' Physical Exercise Habits. Sports Research, 2007, 28 (1): 94-95.

[13] Yang Zhaochang, Hai Mengnan. Survey on Bad Exercise Habits of College Students after School - Taking Northwest University for Nationalities as Example. Fighting (Sports Forum), 2015, 7 (2): $225-$ 227.

[14] Yao Hong'en. Health Fitness Education. Beijing: Higher Education Press, 4th Edition, 2007: 156.

[15] Zhang Mingjun, Du Xinxing \& Gou Bo. Influence of Two Forms of Exercise on Health of Middle-aged Women Working at Desk. Occupation and Health, 2015, 31(3): 310-312. 